\title{
Synthesis, characterization and photocatalytic activity of porphyrin- polyoxometalate hybrid material
}

\author{
Rahmatollah Rahimi, Fatemeh Rafiee, Mahboubeh Rabbani \\ Department of Chemistry, Iran University of Science and Technology, Narmak, Tehran 16846-
}

13114, Iran

\begin{abstract}
In the present work, the preparation of an organic-inorganic hybrid material in which mesotetrakis(phenyl)porphyrin was immobilized on the surface of polyoxometalate $\left(\mathrm{H}_{3} \mathrm{PMo}_{12} \mathrm{O}_{40}\right)$ was reported. This porphyrin-polyoxometalate hybrid material was characterized by FT-IR and UV-Vis spectroscopic methods. The photocatalytic activity of this hybrid material was investigated in the photodegradation of methylene blue.
\end{abstract}

Keywords: Photocatalyst, Porphyrin, Light irradiation, Methylene blue, Polyoxometalate.

\section{Introduction}

Water is a fundamental human need. The wastewater of textile dye draining into the river without treatment would bring out serious pollution of water resource and threatening of ecology environment and human health [1]. So it is essential to develop economic and effective methods for dye waste water treatment [2]. At present, the industrial methods for dye waste treatment include adsorption, precipitation, electrical remediation, oxidation, and biological degradation. But all these ways cost much money, and/ or create secondary contamination. The photocatalytic 
method has been shown to be efficient for degradation and mineralization of various organic pollutants in water at room temperature and normal pressure. The method has potential to be used for treatment of industrial or domestic wastewater on a large scale.

Recently, polyoxomatalates have been studied as new photocatalysts for degradation of organic pollutants. POMs have a number of common features with clusters of metal oxide semiconductor and can be considered as the analogues of the latter (2). Heteropolyacids (HPAs) have both acid and oxidation catalytic function, and therefore, they have been widely employed as homogeneous and heterogeneous catalysts for acid-base and oxidation reactions. Tunable catalytic property of HPA catalysts depending on the identity of counter-cation, central heteroatom, and framework polyatom is another great advantage for their successful catalytic applications [3].

Researches have shown that polyoxometalates (heteropolyacids and their salts, abbreviated herein as POM) and their transition-metal substituted derivatives have the ability of undergoing reversible one or multi-electron transfer while retaining their original structure, which has rendered these compounds attractive acid and redox catalysts in a variety of industrial catalytic applications. As one of the most important visible light photocatalysts, POM-based materials have been actively studied for degradation of synthetic dyes [2].

On other hands, the utility of porphyrin as sensitizers has been an alternative approach in order to extend the absorption range to the visible region $[4,5]$. Porphyrins can participate in various photophysico-chemical processes that are promising solutions for photodynamic therapy of cancer [6]. Due to nontoxicity in the dark and photodegradation in aqueous media [7], porphyrins are attractive in photo decontamination of chemically polluted waters [8]. 
The present work has evaluated the effectiveness of a phorphyrin functionalized POM photocatalysts $\left(\mathrm{TPP} / \mathrm{H}_{3} \mathrm{PMo}_{12} \mathrm{O}_{40}\right)$ for $\mathrm{MB}$ degradation upon LED visible light irradiation, and has made a comparison as well with $\mathrm{H}_{3} \mathrm{PMo}_{12} \mathrm{O}_{40}$. The result shows that $\mathrm{TPP} / \mathrm{H}_{3} \mathrm{PMo}_{12} \mathrm{O}_{40}$ is a good photocatalyst for MB degradation. The schematic structure of $\mathrm{H}_{3} \mathrm{PMo}_{12} \mathrm{O}_{40}$ was shown in Scheme 1.

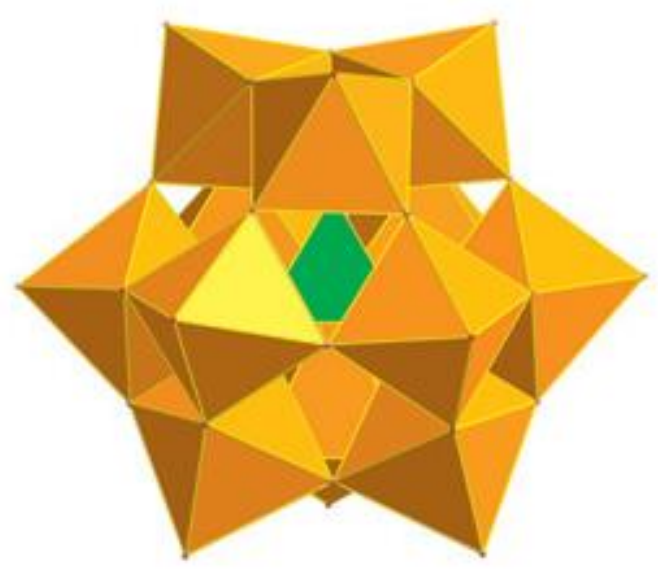

Scheme 1. The schematic structure of $\mathrm{H}_{3} \mathrm{PMo}_{12} \mathrm{O}_{40}$.

\section{Experimental}

\subsection{Materials and Methods}

All of the Chemicals used in this work were analytical grade reagents and used without further purification. Deionized water was used to preparation of all solutions.

The FT-IR analyses were carried out on a Shimadzu FTIR-8400S spectrophotometer using a $\mathrm{KBr}$ pellet for sample preparation. DRS spectra were prepared via a Shimadzu (MPC-2200) spectrophotometer.

\subsection{Synthesis of $\mathrm{H}_{3} \mathrm{PMo}_{12} \mathrm{O}_{40}$}


The heteropolyoxometalate $\mathrm{H}_{3} \mathrm{PMo}_{12} \mathrm{O}_{40}$ was prepared according to literature procedures [9]. To $200 \mathrm{ml}$ of a $3 \mathrm{M}$ solution of $\mathrm{Na}_{2} \mathrm{MoO}_{4}$ were added successively $3.5 \mathrm{ml}$ of $85 \% \mathrm{H}_{3} \mathrm{PO}_{4}$ and $150 \mathrm{ml}$ of $70 \% \mathrm{HClO}$. After the mixture was cooled to room temperature, the disodium salt $\mathrm{Na}_{2} \mathrm{HPMo}_{12} \mathrm{O}_{40}$ was precipitated. The microcrystalline powder was filtered and air dried.

$\mathrm{H}_{3} \mathrm{PMo}_{12} \mathrm{O}_{40}$ was obtained from a solution of $50 \mathrm{~g} \mathrm{Na}_{2} \mathrm{HPMo}_{12} \mathrm{O}_{40}$ in $50 \mathrm{ml}$ of $\mathrm{H}_{2} \mathrm{O}$, acidified by $10 \mathrm{ml}$ of $37 \% \mathrm{HC} 1$, and extracted by $80 \mathrm{ml} \mathrm{Et}_{2} \mathrm{O}$. When water was added to the denser layer, yellow crystals of $\mathrm{H}_{3} \mathrm{PMo}_{12} \mathrm{O}_{40}$ precipitated.

\subsection{Synthesis of TPP}

$10 \mathrm{mmol}$ of freshly distilled pyrrole $(0.7 \mathrm{~mL}), 10 \mathrm{mmol}$ of benzaldehyde, $100 \mathrm{~mL}$ of propionic acid and $15 \mathrm{~mL}$ of nitrobenzene were added together in a $250 \mathrm{~mL}$ flask. The mixture was allowed to reflux under stirring at $120{ }^{\circ} \mathrm{C}$ for $60 \mathrm{~min}$. After that, the resulting mixture was cooled overnight in room temperature and filtrated under reduced pressure. The crude product was purified by column chromatography (Silica gel, chloroform/ethyl acetate $=20: 1$ as an eluent) and a desired purple solid of meso-tetrakis(phenyl)porphyrin (TPP) was obtained (30\%).

\subsection{Immobilization of TPP on $\mathrm{H}_{3} \mathrm{PMo}_{12} \mathrm{O}_{40}$}

$0.2 \mathrm{~g}$ of TPP was dissolved in $50 \mathrm{ml}$ of DMF and $2 \mathrm{~g}$ of finely grounded $\mathrm{H}_{3} \mathrm{PMo}_{12} \mathrm{O}_{40}$ was added to this solution. The resulting suspension was stirred under refluxing for $24 \mathrm{~h}$ and then the solvent was removed under vacuum at room temperature. The resulting solution was cooled in room temperature for $24 \mathrm{~h}$. Consequently, the product was washed with DMF until no porphyrin could be detected in the supernatant by UV-visible spectrophotometer. 


\subsection{Photocatalysis procedure}

In a typical process, the catalytic reaction was carried out in a $100 \mathrm{ml}$ photoreactor, which contain $50 \mathrm{ml}$ of $\mathrm{MB}$ dye $\left(200 \mathrm{mgl}^{-1}\right)$ solution and $0.05 \mathrm{~g}$ of catalyst $\left(\mathrm{TPP} / \mathrm{H}_{3} \mathrm{PMo}_{12} \mathrm{O}_{40}\right.$ and $\left.\mathrm{H}_{3} \mathrm{PMo}_{12} \mathrm{O}_{40}\right)$. Before the irradiation, the solution was stirred in the dark $(15 \mathrm{~min})$ to allow equilibrium of the system. Irradiation was carried out using LED visible light sources. All photocatalytic experiments were carried out at the same conditions. The distance between photoreactor and light sources was $20 \mathrm{~cm}$. Samples $(3 \mathrm{ml})$ were collected during the irradiation and $\mathrm{MB}$ solution were separated from the photocatalyst by centrifugation. The degradation was monitored by measuring the absorbance amount using a double beam UV-vis spectrophotometer (Shimadzu UV-1700) at $664 \mathrm{~nm}$ wavelength.

\section{Results and discussion}

Fig. 1 shows the FT-IR spectra of the TPP. The stretching vibration of $=\mathrm{C}-\mathrm{N}$ and $-\mathrm{C}=\mathrm{N}$ bands (pyrrole) appeared at $1373 \mathrm{~cm}^{-1}$ and $1720 \mathrm{~cm}^{-1}$, respectively. The stretching asymmetric and symmetric vibration bands attributed to the $\mathrm{C}-\mathrm{H}\left(\mathrm{CH}_{2}\right)$ band are discernible in 2846, 2918 and $2939 \mathrm{~cm}^{-1}$. The appearance of the peaks at $890 \mathrm{~cm}^{-1}$ could be attributed to $\mathrm{C}_{6} \mathrm{H}_{4}$ (phenyl).

Fig. 2 shows the FT-IR spectra of $\mathrm{H}_{3} \mathrm{PMo}_{12} \mathrm{O}_{40}$, TPP/ $\mathrm{H}_{3} \mathrm{PMo}_{12} \mathrm{O}_{40}$ and $\mathrm{TPP} / \mathrm{H}_{3} \mathrm{PMo}_{12} \mathrm{O}_{40}+\mathrm{MB}$ measured in the range of $390-4000 \mathrm{~cm}^{-1}$. In the FT-IR spectrum of molybdophosphoric acid, its characteristic bands at $1064 \mathrm{~cm}^{-1}$ due to stretching of $\mathrm{P}-\mathrm{O}, 962 \mathrm{~cm}^{-1}$ to stretching of $\mathrm{Mo}=\mathrm{O}, 870$ $\mathrm{cm}^{-1}$ to stretching of Mo-O-Mo, and $775 \mathrm{~cm}^{-1}$ to stretching of another Mo-O-Mo are observed. For the FT-IR spectra of TPP/ $\mathrm{H}_{3} \mathrm{PMo}_{12} \mathrm{O}_{40}$ and $\mathrm{TPP} / \mathrm{H}_{3} \mathrm{PMo}_{12} \mathrm{O}_{40}+\mathrm{MB}$, the appearance of peaks corresponded to TPP confirm that porphyrin have immobilized on PMO but these peaks are 
difficult to give precise values because of very low intensities due to a low loading of the macrocycle into the inorganic matrix.

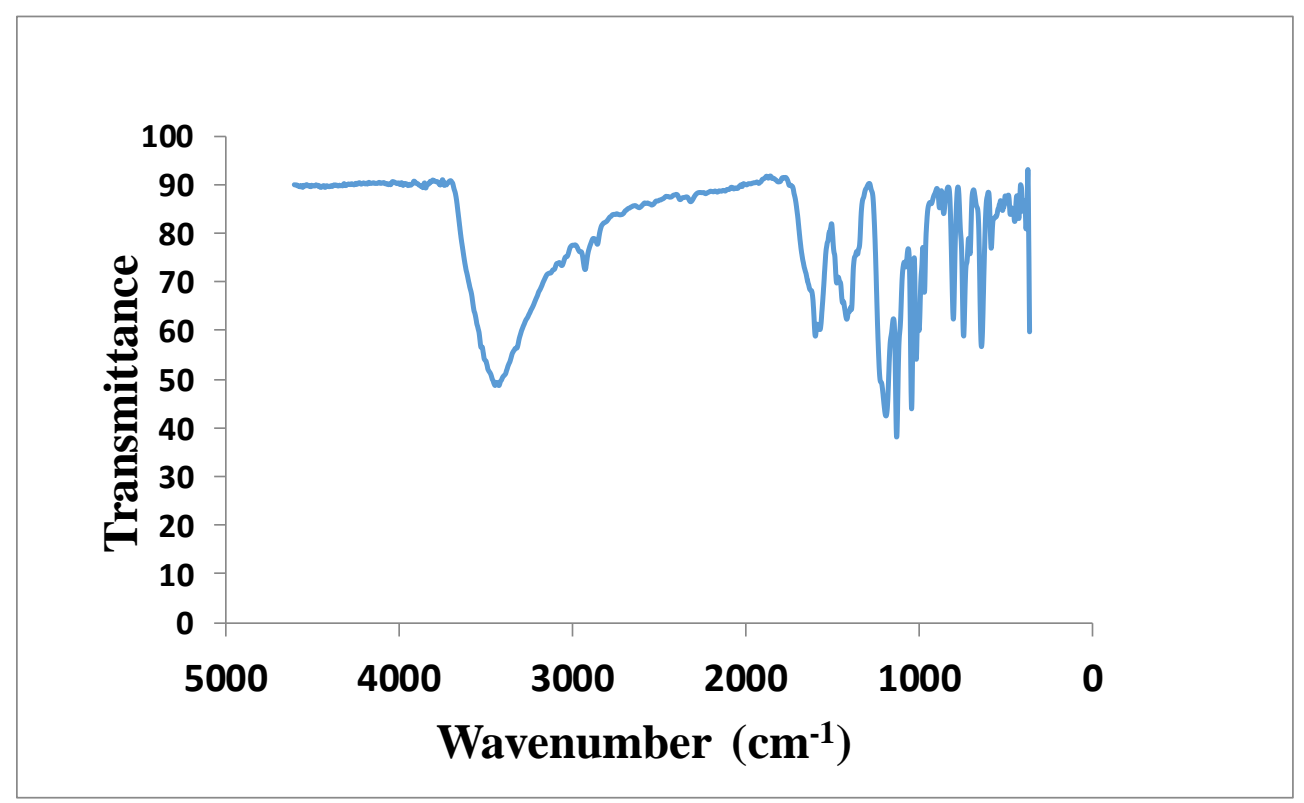

Fig. 1 The FT-IR spectra of the TPP.

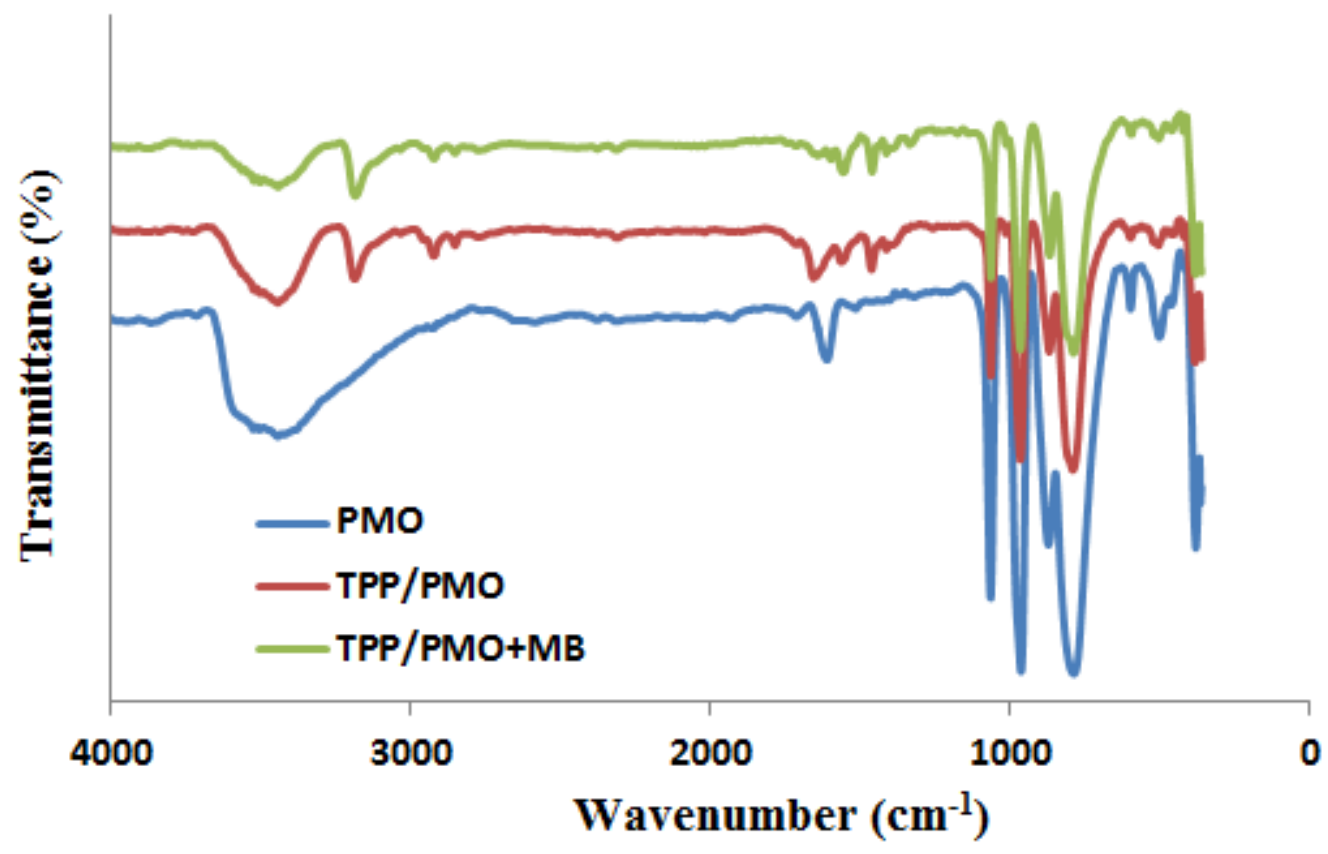

Fig. 2 The FT-IR spectra of $\mathrm{H}_{3} \mathrm{PMo}_{12} \mathrm{O}_{40}, \mathrm{TPP} / \mathrm{H}_{3} \mathrm{PMo}_{12} \mathrm{O}_{40}$ and $\mathrm{TPP} / \mathrm{H}_{3} \mathrm{PMo}_{12} \mathrm{O}_{40}+\mathrm{MB}$. 
Fig. 3 shows the UV-Vis spectrum of TPP in DMF. The UV-vis diffuse reflectance spectrum (DRS) of the synthesized TPP/ $\mathrm{H}_{3} \mathrm{PMo}_{12} \mathrm{O}_{40}$ is shown in Fig. 4.

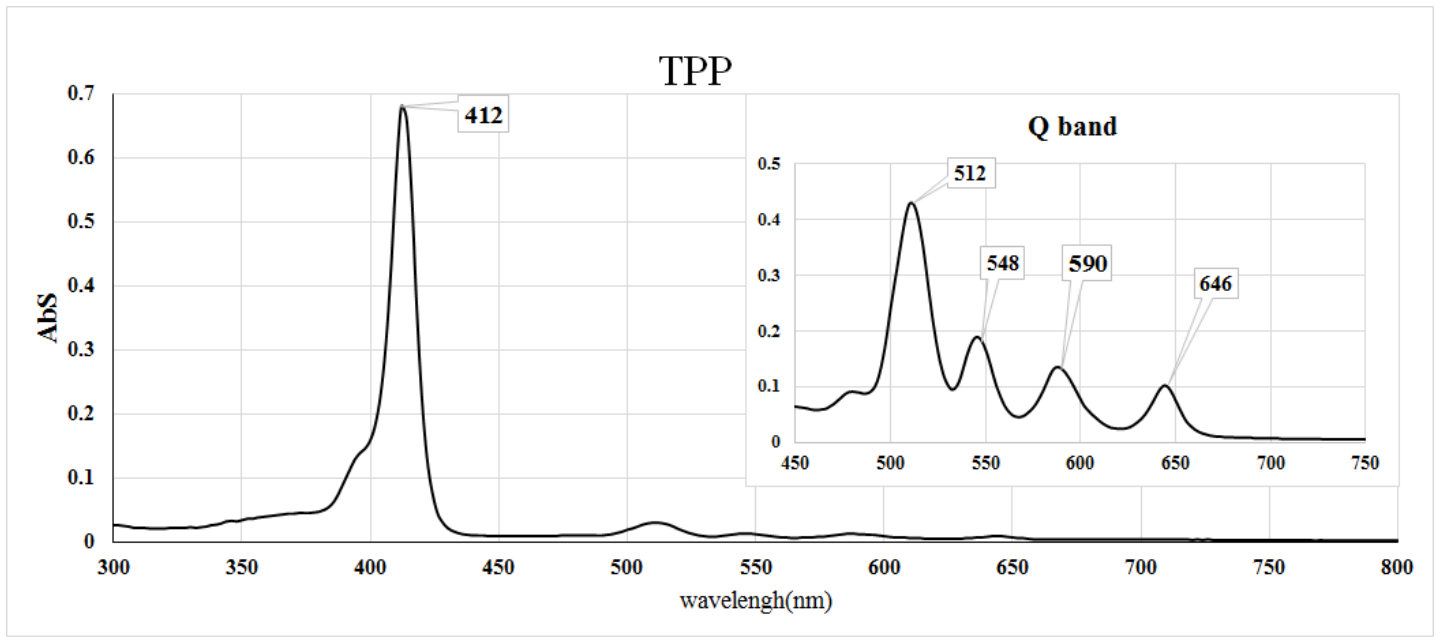

Fig. 3. The UV-Vis spectra of TPP in DMF.

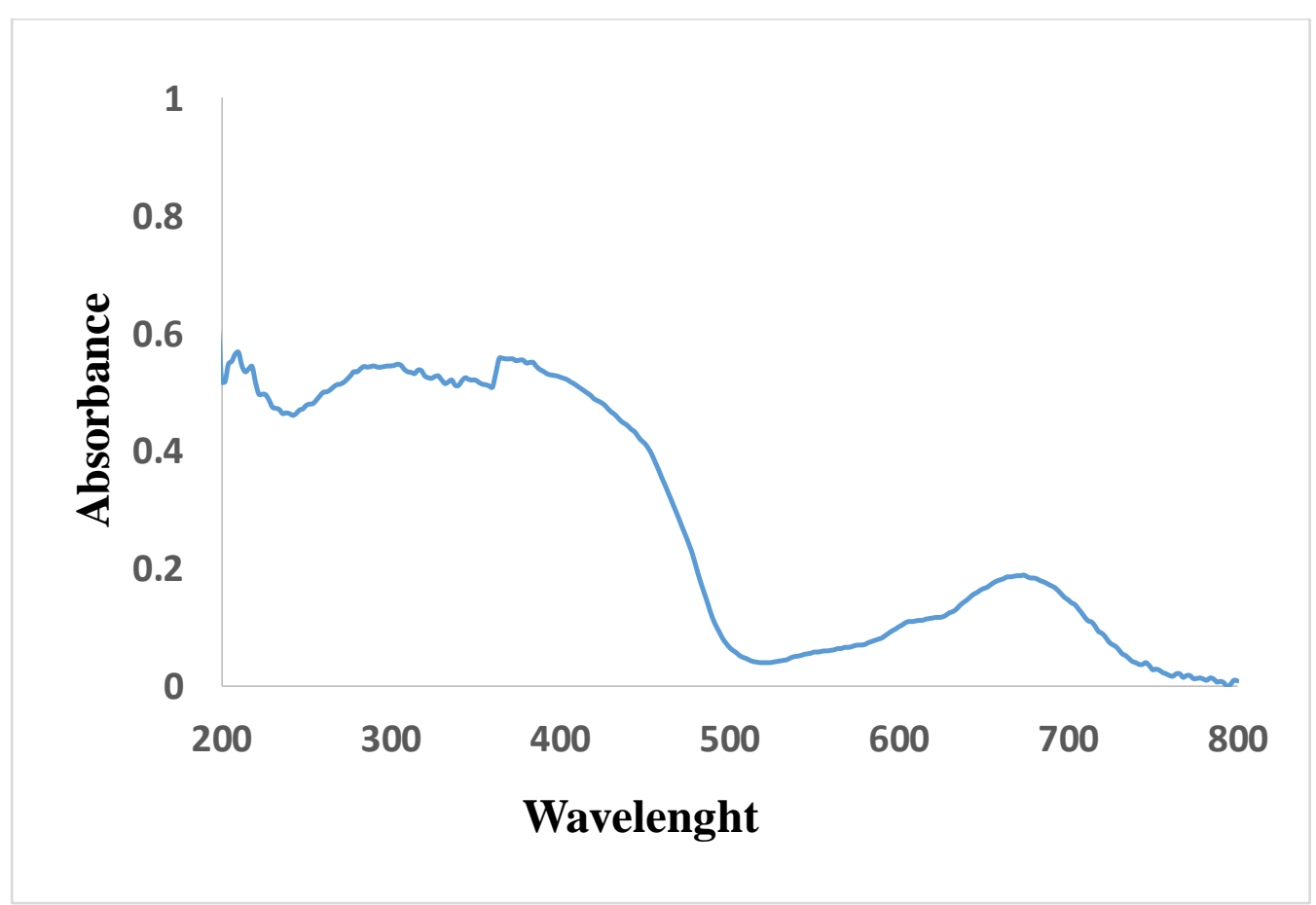


Fig. 4. The UV-Vis spectra of $\mathrm{TPP} / \mathrm{H}_{3} \mathrm{PMo}_{12} \mathrm{O}_{40}$.

The photocatalytic activities of as-synthesized $\mathrm{TPP} / \mathrm{H}_{3} \mathrm{PMo}_{12} \mathrm{O}_{40}$ catalysts were evaluated by the degradation of MB in aqueous solution under LED visible light irradiation. The characteristic absorption of $\mathrm{MB}$ at $664 \mathrm{~nm}$ was chosen to monitor the photocatalytic degradation process. Concerning the initial MB concentration, it can be concluded that there was a decrease in the photodegradation of MB with increasing initial MB concentration. Fig. 5 shows the UV-Vis spectra of MB with concentration of $10 \mathrm{mgl}^{-1}$.

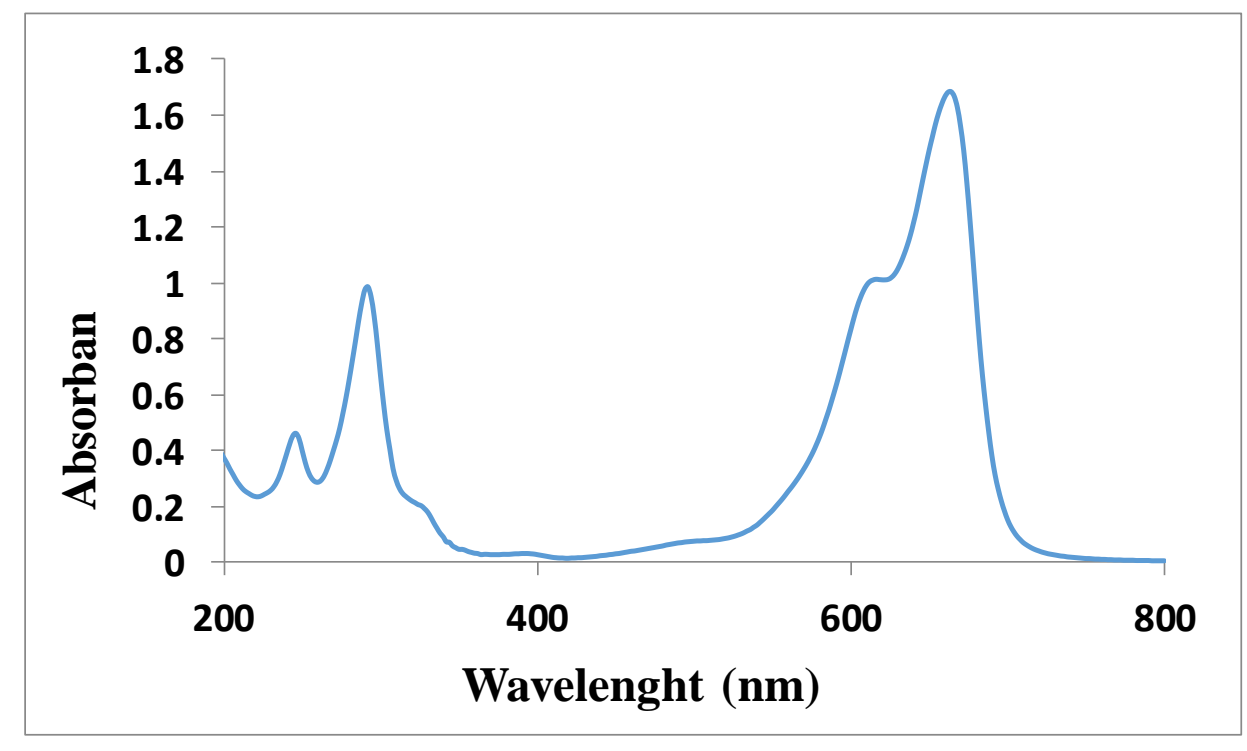

Fig. 5. The absorption spectra of the MB solution with concentration of $10 \mathrm{mgl}^{-1}$.

Fig. 6 show the photocatalytic efficiency of photocatalytic degradation of MB by $\mathrm{TPP} / \mathrm{H}_{3} \mathrm{PMo}_{12} \mathrm{O}_{40}$ and $\mathrm{H}_{3} \mathrm{PMo}_{12} \mathrm{O}_{40}$ without light and under light irradiation. The best photodegradation of $\mathrm{MB}$ was carried using $\mathrm{TPP} / \mathrm{H}_{3} \mathrm{PMo}_{12} \mathrm{O}_{40}$ under light irradiation (85\%), while 
in dark condition, it can be seen that $\mathrm{H}_{3} \mathrm{PMo}_{12} \mathrm{O}_{40}$ photocatalyst has the lowest activation and can lead to only $45 \%$ decompositions of MB after 180 min illumination.

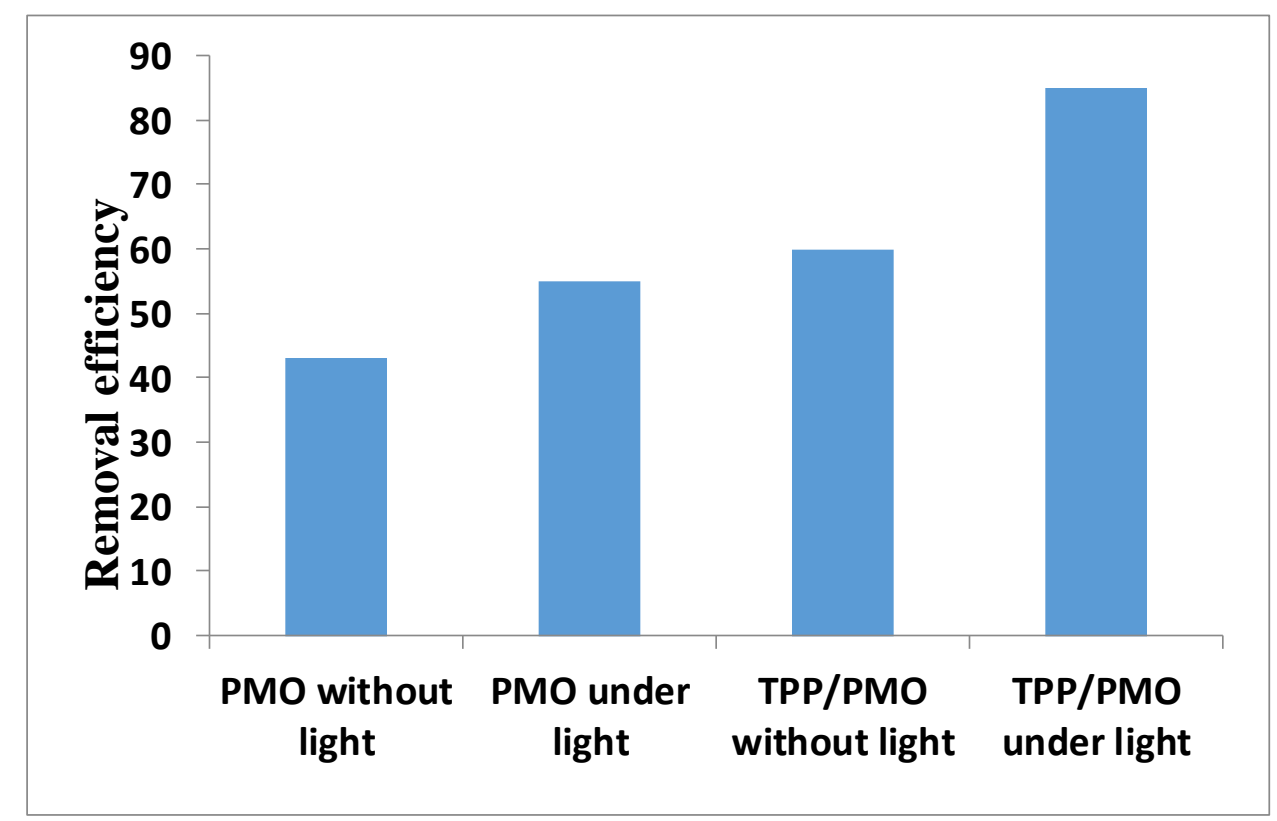

Fig. 6. The removal efficiency of photocatalytic degradation of $M B$ by $T P P / \mathrm{H}_{3} \mathrm{PMo}_{12} \mathrm{O}_{40}$ and $\mathrm{H}_{3} \mathrm{PMo}_{12} \mathrm{O}_{40}$ without light and under light irradiation

\section{Conclusions}

This report has showed that the textile dye of MB in water can be degraded by LED light irradiation in the presence of $\mathrm{TPP} / \mathrm{H}_{3} \mathrm{PMo}_{12} \mathrm{O}_{40}$ and $\mathrm{H}_{3} \mathrm{PMo}_{12} \mathrm{O}_{40}$. For this reaction, $\mathrm{TPP} / \mathrm{H}_{3} \mathrm{PMo}_{12} \mathrm{O}_{40}$ is much more efficient than $\mathrm{H}_{3} \mathrm{PMo}_{12} \mathrm{O}_{40}$.

\section{References:}

[1] Meiqin $\mathrm{Hu}$, Yiming $\mathrm{Xu}$, Photocatalytic degradation of textile dye $\mathrm{X} 3 \mathrm{~B}$ by heteropolyoxometalate acids, Chemosphere 54 (2004) 431-434 
[2] Sanni Ma,JianqiangMeng, JinghuaLi, YufengZhang,LeiNi, Synthesis of catalytic polypropylene membranes enabling visible-light-driven photocatalytic degradation of dyes in water, Journal ofMembraneScience453(2014)221-229

[3] Heesoo Kim, Ji Chul Jung, Pil Kim, Sung Ho Yeom, Kwan-Young Lee, In Kyu Song, Preparation of H3PMo12O40 catalyst immobilized on surface modified mesostructured cellular foam (SM-MCF) silica and its application to the ethanol conversion reaction, Journal of Molecular Catalysis A: Chemical 259 (2006) 150-155

[4] W.-j. Sun, J. Li, G. Mele, Z.-q. Zhang, F.-x. Zhang, Enhanced photocatalytic degradation of rhodamine $\mathrm{B}$ by surface modification of $\mathrm{ZnO}$ with copper (II) porphyrin under both $\mathrm{UV}$-vis and visible light irradiation, Journal of Molecular Catalysis A: Chemical, (2012).

[5] R. Gerdes, D. Wöhrle, W. Spiller, G. Schneider, G. Schnurpfeil, G. Schulz-Ekloff, Photooxidation of phenol and monochlorophenols in oxygen-saturated aqueous solutions by different photosensitizers, Journal of Photochemistry and Photobiology A: Chemistry, 111 (1997) 65-74.

[6] E.S. Nyman, P.H. Hynninen, Research advances in the use of tetrapyrrolic photosensitizers for photodynamic therapy, Journal of Photochemistry and Photobiology B: Biology, 73 (2004) 128.

[7] R. Rotomskis, G. Streckyte, S. Bagdonas, Phototransformations of sensitizers 1. Significance of the nature of the sensitizer in the photobleaching process and photoproduct formation in aqueous solution, Journal of Photochemistry and Photobiology B: Biology, 39 (1997) 167-171.

[8] A.C. Herath, R. Rajapakse, A. Wicramasinghe, V. Karunaratne, Photodegradation of triphenylamino methane (magenta) by photosensitizer in oxygenated solutions, Environmental science \& technology, 43 (2008) 176-180. 
[9] Tayebee, R. and M.H. Alizadeh, Water as an efficient solvent for oxygenation transformations with $34 \%$ hydrogen peroxide catalyzed by some heteropolyoxometalates. Monatshefte für Chemie-Chemical Monthly, 2007. 138(8): 763-769. 